\title{
Clonidine, but not Guanfacine, Impairs Choice Reaction Time Performance in Young Healthy Volunteers
}

P. Jäkälä, M.D., Ph.D., M. Riekkinen, M.D., Ph.D., J. Sirviö, Ph.D., E. Koivisto, M.Sc., and P. Riekkinen Jr., M.D., Ph.D.

The present study compares the effects of two $\alpha_{2}-$ adrenoceptor agonists, clonidine (0.5, 2, and $5 \mu \mathrm{g} / \mathrm{kg}$, p.o.), and guanfacine (7 and $29 \mu \mathrm{g} / \mathrm{kg}$, p.o.), in young healthy volunteers on attentional performance. A placebo-controlled double-blind cross-over design (one drug dose/group) was employed. Neither of the drugs affected measures of motor performance or performance at easy levels in an attentional test. However, at the most difficult level in the attentional test, the highest dose of clonidine ( $5 \mu \mathrm{g} / \mathrm{kg}$ ), but not guanfacine, decreased the number of correct responses and increased reaction latency. Clonidine 5 and guanfacine 29 $\mu \mathrm{g} / \mathrm{kg}$ equally increased subjective feelings of sedation and reduced systolic and diastolic blood pressures. Thus, the effects of the drugs on attentional performance could be dissociated from their sedative effects. The results demonstrate that clonidine, but not guanfacine, disrupts performance in an attentional task requiring effortful processing, while leaving performance intact in tests requiring more automatic processing. The lower $\alpha_{2 A^{-}}$vs. $\alpha_{2 c}$-adrenoceptor selectivity ratio of clonidine and the affinity for $\alpha_{1}$-adrenoceptors of clonidine may be responsible for the different action of these drugs on attention.

[Neuropsychopharmacology 21:495-502, 1999] (C) 1999 American College of Neuropsychopharmacology. Published by Elsevier Science Inc.
KEY WORDS: Adrenergic- $\alpha_{2}$-Agonist-pharmacology; Attention-drug-effects; Clonidine-pharmacology; Guanfacine-pharmacology; Noradrenaline-pharmacology; $\alpha_{2}$-receptors, -Adrenergic, $-\alpha_{2}$-drug-effects

Noradrenaline-containing neurons of the locus coeruleus (LC), arising from the brainstem, form one of the ascending modulatory systems innervating the forebrain (Foote and Morrison 1987). Electrophysiological studies have demonstrated that the LC noradrenergic

From the Department of Neuroscience and Neurology, University and University Hospital of Kuopio, Kuopio, Finland.

Address correspondence to: Paavo Riekkinen Jr., M.D., Ph.D. Department of Neuroscience and Neurology, University and University Hospital of Kuopio, P.O.B. 1627, FIN-70211, Kuopio, Finland.

Received October 24, 1998; accepted January 27, 1999. system plays an important role in arousal, vigilance, and responses to novel, salient stimuli (Foote and Morrison 1987; Harley 1987; McCormick 1989; Aston-Jones et al. 1990; Berridge and Foote 1991; Riekkinen P Jr et al. 1993). The firing rate of LC noradrenergic neurons is regulated by $\alpha_{2}$-adrenergic autoreceptors (Aghajanian et al. 1977; Aghajanian and VanderMaelen 1982; Arnsten 1998). Activation of these receptors causes autoinhibition of noradrenergic neurons, whereas blockade of these receptors increases the firing rate of LC neurons and the release and turnover of noradrenaline in brain (Cederbaum and Aghajanian 1976; Langer 1987). However, a major portion of $\alpha_{2}$-adrenoceptors is localized on non-noradrenergic cells that receive a noradrenergic input, i.e., post-synaptic to LC noradrenergic neurons (U'Prichard et al. 1979; Aoki et al. 1994; Scheinin et al. 1994). 
Using a single test of sustained attention and vigilance, i.e., the five-choice serial reaction time task, it has been possible to probe the neurochemical basis of attention in rats (see Robbins and Everitt 1994). In this task, lesion of the ascending LC projections in the dorsal noradrenergic bundle $(\mathrm{DNAB})$ reduces accuracy if the visual targets are presented unpredictably or the rats are distracted by bursts of white noise (Carli et al. 1983; Cole and Robbins 1987; Cole and Robbins 1992), suggesting that DNAB lesion selectively impairs effortful or controlled information processing occurring in a novel situation or in a situation placing an additional load on attention processing resources, while leaving automatic processing and well trained performance, largely unchanged (Cole and Robbins 1992). In the same task, an $\alpha_{2}$-adrenoceptor agonist, dexmedetomidine, increases errors of omission and decreases behavioral activity (Sirviö et al. 1994), whereas an $\alpha_{2}$-adrenoceptor antagonist, atipamezole, increases the number of premature responses indicating facilitation of behavioral activation (Jäkälä et al. 1992; Sirviö et al. 1993), and improves choice accuracy under reduced stimulus intensity conditions (Sirviö et al. 1993).

There is evidence for a role for the $\alpha_{2}$-system in the modulation of attentional functions in humans: 1) In a sustained attention task, such as a rapid visual information processing task, clonidine impairs performance (Coull et al. 1995a, 1995b); 2) clonidine broadens the focus of attention (Clark et al. 1989; Coull et al. 1995a, 1995b), whereas an $\alpha_{2}$-adrenoceptor antagonist, idazoxan, narrows the focus of attention (Smith et al. 1992); 3) another $\alpha_{2}$-adrenoceptor antagonist, atipamezole, improves focused attention and impairs behavioral and electrophysiological measures of divided attention (Mervaala et al. 1993); and 4) clonidine impairs performance in a focused attention task, and this can be reversed by idazoxan (Smith and Nutt 1996).

Importantly, three subtypes of $\alpha_{2}$-adrenoceptors $\left(\alpha_{2 \mathrm{~A}}, \alpha_{2 \mathrm{~B}}\right.$ and $\left.\alpha_{2 \mathrm{C}}\right)$ have now been cloned in humans (Kobilka et al. 1987; Regan et al. 1988; Lomasney et al. 1990). The three subtypes have a distinct distribution in the brain areas involved in separate functional systems (Scheinin et al. 1994), suggesting that modulation of these subtypes by subtype selective ligands might possess qualitatively different actions (MacDonald et al. 1997). For example, the hypotensive and sedative actions of dexmedetomidine were abolished in $\alpha_{2 A^{-}}$ adrenoceptor functional knock out mice (MacMillan et al. 1996) that correlates with the presence of a high density of $\alpha_{2 \mathrm{~A}}$-adrenoceptors in the nucleus tractus solitarius and LC (Scheinin et al. 1994). In the monkey prefrontal cortex, the $\alpha_{2 \mathrm{~A}}$ subtype has the densest distribution of all the three subtypes (Aoki et al. 1994), and the ability of non-subtype selective $\alpha_{2}$-adrenoceptor agonists to improve prefrontal cortical functions, i.e., spatial working memory performance, without adverse events in monkeys corresponded to their relative selectivity for the $\alpha_{2 \mathrm{~A}}$ site (i.e., guanfacine $>\mathrm{UK}-14304>$ clonidine $>$ BHT920) (see Arnsten et al. 1996). Importantly, the beneficial effect of dexmedetomidine, an $\alpha_{2}$-adrenoceptor agonist, on spatial working memory function is not diminished by $\alpha_{2 \mathrm{C}}$-adrenoceptor knock out in mice (Tanila et al. in press). Furthermore, overexpression of $\alpha_{2 C}$-adrenoceptors retarded the accuracy of the mutant mice in a water maze spatial memory test and administration of an $\alpha_{2}$-adrenoceptor antagonist, atipamezole, fully reversed the deficit induced by overexpression of $\alpha_{2 \mathrm{C}}$-adrenoceptors in mice (Björklund et al. 1998). Dexmedetomidine impaired water maze spatial memory only in wild type mice, but not in $\alpha_{2 \mathrm{C}}$-adrenoceptor knock out mice (Björklund et al. 1998, 1999). These results indicate that stimulation of $\alpha_{2 \mathrm{~A}}$-adrenoceptors mediates the effects on working memory function (Tanila et al. in press) and that activation of $\alpha_{2 C}$-adrenoceptors may even diminish the beneficial actions of $\alpha_{2}$-adrenoceptor agonists on cognitive functioning (Björklund et al. 1998). Furthermore, in humans administration of guanfacine more effectively stimulated spatial working memory than clonidine treatment (Jäkälä et al. 1999) that may be related to higher $\alpha_{2 A} / \alpha_{2 C}$ affinity ratio of guanfacine. Indeed, $\alpha_{2 C}$ adrenoceptors are also found in the LC (Lee et al. 1998) and clonidine may more effectively modulate activity of these receptors than guanfacine. Therefore, it is possible that clonidine may more effectively than guanfacine inhibit LC firing and impair function of the ascending noradrenergic fibers in the modulation of attention. We designed the present study to compare whether clonidine disrupts attention more effectively than guanfacine in young healthy subjects.

\section{METHODS}

\section{Subjects}

Five separate groups of normal (as indicated by WAIS$\mathrm{R}$ Vocabulary subtest and verbal fluency tests) (Borkowski et al. 1967; Wechsler 1992) healthy young volunteers (aged 23-35 years, $n=43 ; 28$ males and 15 females) took part in the drug study. None of the volunteers were receiving concurrent medication, nor had a history of psychiatric, neurologic or cardiovascular illnesses or other medical conditions that could interfere with central nervous system functions or interpretation of the results. The studies were approved by the local ethics committee and national drug regulatory authority, and all subjects provided written informed consent. All subjects were covered by insurance.

\section{Pharmacological Manipulations}

Five different experimental groups were formed. Groups 1 ( $n=6 ; 5$ males and 1 female), $2(n=8 ; 7$ males 
and 1 female), and 3 ( $n=8 ; 7$ males and 1 female) received $0.5,2.0$, and $5.0 \mu \mathrm{g} / \mathrm{kg}$, respectively, of clonidine hydrochloride (Catapressan ${ }^{\circledR}$, Boehringer Ingelheim), p.o. in tablet form, or appropriate oral placebo, $90 \mathrm{~min}$ before starting the test session. Groups 4 ( $n=9 ; 4$ males and 5 females) and 5 ( $n=12 ; 5$ males and 7 females) received 7 and $29 \mu \mathrm{g} / \mathrm{kg}$, respectively, of guanfacine hydrochloride (Estulic ${ }^{\circledR}$, Sandoz Oy), p.o. in tablet form, or appropriate oral placebo, $90 \mathrm{~min}$ before starting the test session.

\section{Procedure and Experimental Design}

Subjects from each group attended on two occasions (at least seven days between sessions), and received the relevant pharmacological manipulation on one occasion, and an appropriate placebo on the other in a counterbalanced order for each group (placebo-controlled double-blind cross over design) (Hills and Armitage 1979). Both the subject and the investigator were blinded to the composition of the tablets. Experimental sessions were started at the same time of each testing day for each individual subject. The attentional tasks were given as a part of our larger-scale project investigating the effects of $\alpha_{2}$-adrenergic drugs on executive, attentional and working memory functions. The entire test session lasted 60-90 min for all the subjects, and the testing began 90 min post-ingestion of tablets for all the subjects.

\section{Neuropsychological Tests}

These tasks are part of the CANTAB (Paul Fray Co.) attention battery (Downes et al. 1989) and were run on an IBM PS/2 Model 30486 personal computer, with a high resolution Taxan $770+$ colour monitor fitted with an Intasolve touch-sensitive screen.

\section{Motor Screening Test}

In this test, a series of crosses was shown in different locations on the screen. After a demonstration of the correct way to point, the subjects had to point to crosses as they appeared on the screen as quickly and accurately as possible. The test has two purposes. First, it acted as a training procedure to ensure that the subjects can point accurately, and second, measures of speed and accuracy were taken which provided an index of the subjects' motor performance. The mean of ten trials for both the latency in milliseconds to point accurately to a cross after it appeared, and accuracy ("error"), i.e., the distance in millimeters between the first point touched by the subject and the actual cross, were recorded (Table 1).
Table 1. Effects of Clonidine and Guanfacine on the Test of Speed of Motor Performance (Motor Screening Test)

\begin{tabular}{lcc}
\hline & Placebo & Drug \\
\hline C 0.5 & $792 \pm 225$ & $778 \pm 201$ \\
C 2 & $799 \pm 201$ & $821 \pm 179$ \\
C 5 & $772 \pm 205$ & $778 \pm 221$ \\
G 7 & $821 \pm 270$ & $942 \pm 312$ \\
G 29 & $802 \pm 184$ & $770 \pm 164$ \\
\hline
\end{tabular}

The means of ten trials \pm S.D. for the latency to point in milliseconds are shown. C, clonidine; G, guanfacine.

Doses are expressed as $\mu \mathrm{g} / \mathrm{kg}$. Neither of the drugs affected latency or accuracy of responding in this test.

\section{Simple and Choice Reaction Time Test}

There were five ascending levels of difficulty in this test, the first four of which acted as training exercises to prepare the subjects for the final level. In the first stage, subjects simply had to touch the screen when a yellow dot appeared in the centre, neither being too early nor too late. The choice reaction was introduced at the second stage, with the dot now appearing in one of five locations. Subjects were introduced to the use of a touch pad at the third level. They were required to release their hand from a touch pad as quickly as possible after a dot appeared in a single location on a screen. The requirement to release the pad was then combined with the requirement to touch the screen at the fourth level. Subjects were required to hold down the touch pad until a single dot appeared in the centre of the screen and then to touch the position of the dot as quickly as possible (Simple Reaction Time Test). They were then considered to be adequately trained for the fifth and final level, a Choice Reaction Time Test. They were required to hold down the touch pad until the dot appeared at one of five locations on the screen, and then point to the position on the screen where the dot was presented as quickly as possible. Stimulus display time was $250 \mathrm{msec}$ for all the stages, and the response was considered correct if the subject touched the dot when it was displayed on the screen or the correct position of the dot within $5000 \mathrm{msec}$ after the dot had disappeared from the screen (limited hold). Inter trial interval was 1000 msec for all the stages. At the first three stages, subjects were required to reach a criterion of $5 / 6$ correct within 18 trials to go on to the next stage. At the fourth stage, subjects continued until a criterion of $5 / 6$ was reached or 18 trials had been completed. All the subjects in this study reached a criterion of $5 / 6$ in the first four stages. Then, at the fifth stage, the subjects were required to reach a criterion of $7 / 8$ correct within a maximum of 40 trials. Both accuracy (the number of correct responses and the number of total moves at each stage) and speed of response were recorded. For stages 4 (Simple Reaction Time Test) and 5 (Choice Reaction Time Test), the speed of response was divided into reaction latency (la- 
tency to release the touch pad) and movement latency (from release of touch pad to touch of the screen).

\section{Visual Analogue Scale}

After completion of the test session, the subjects were asked to rate themselves for subjective feelings of "sedation/tiredness" by asking them to place a mark on a $100 \mathrm{~mm}$ line numbered from 1 to 10 , with 1 representing "not at all" and 10 representing "very much."

\section{Monitoring of Blood Pressure}

Blood pressure of the subjects was measured before they received the study drugs or matching placebo tablets, 90 min afterwards (i.e., just before beginning of the test session), and after completion of the test session which lasted for 60-90 min.

\section{Statistical Analysis}

The repeated measures cross-over design may carry with it the problem of practice effects, which may confound the validity of the statistical interactions. To reveal possible practice effects in these tasks, we had beforehand tested a separate group of normal young healthy control subjects $(n=12)$ without any drug treatment with the same test battery on two occasions with no less than one week between sessions. No significant effects on the parameters analyzed in the present study were found (data not shown). The number of total responses, the number of correct responses and the reaction latency at the stage 5 (Choice Reaction Time Test) was used as the primary performance measures, as our preliminary studies revealed stages $1-4$ to be too easy to detect subtle accuracy defects. However, we observed that clonidine in this study impaired accuracy at the stage 5 . Therefore, the accuracy of performance at stages 1-4 was analyzed to evaluate whether the effects of clonidine on accuracy at stage 5 were due to inferior performance at easier task levels. Repeated measures ANOVA was used to analyze treatment group 1-5, repetition (i.e., values measured after placebo and drug), order of treatment and sex effects and their interactions with performance. Paired samples T-test was used in within group comparison of the present data. Values with $p<.05$ were considered significant.

\section{RESULTS}

\section{Motor Screening Test}

Neither clonidine $(0.5,2.0$, and $5.0 \mu \mathrm{g} / \mathrm{kg}$ ) nor guanfacine $(7$ and $29 \mu \mathrm{g} / \mathrm{kg})$ at any of the doses tested affected latency to point accurately to a cross (Table 1) or the accuracy (data not shown), i.e., the distance between the first point touched by the subject and the actual cross (group effect: $\mathrm{F}(4,29)=1.7, p=.17$ ).

\section{Simple and Choice Reaction Time Test}

In stages $1-4$ of this test, no drug treatment effects by clonidine or guanfacine on the number of correct responses, number of total moves or reaction latency were found (data not shown; group effect: $F(4,29)=$ $0.3, p>.1$, for all). However, in the Choice Reaction Time Test (stage 5), clonidine at the highest dose used $(5.0 \mu \mathrm{g} / \mathrm{kg})$ significantly decreased the number of correct responses (group by repetition interaction: $\mathrm{F}(4,29)=$ $3.32, p<.05$; placebo vs. clonidine $5 \mu \mathrm{g} / \mathrm{kg}: T=-5.92$, $d f=7, p<.05)$, and increased the reaction latency (group by repetition interaction: $\mathrm{F}(4,29)=2.7, p<.05$; placebo vs. clonidine $5 \mu \mathrm{g} / \mathrm{kg}: T=-4.30, d f=7, p<$ $.05)$. Lower doses of clonidine $(0.5$ and $2.0 \mu \mathrm{g} / \mathrm{kg})$ or guanfacine (7 and $29 \mu \mathrm{g} / \mathrm{kg}$ ) had no effect on the number of correct responses or reaction latencies in this stage (placebo vs. drugs: $p>.05$ for all). The number of total moves in Choice Reaction Time Test (stage 5) was not affected by any of the doses of clonidine or guanfacine (group effect: $F(4,29)<0.5, p>.5$ for all). The combined movement latency from stages 4 (Simple Reaction Time Test) and 5 (Choice Reaction Time Test) was not affected by the treatments (group effect: F(4, $29)=0.12, p=.13$ ) (data not shown). There were no significant sex or order effects or interactions between sex, order and drug group (data not shown).

\section{Visual Analogue Scale}

Clonidine and guanfacine at the highest doses used (5 and $29 \mu \mathrm{g} / \mathrm{kg}$, respectively) increased the subjective feelings of sedation vs. placebo (group by repetition interaction: $\mathrm{F}(4,29)=3.2, p<.5, T=-4.02, d f=7, T=$ $-3.14, d f=11$, respectively, $p<.05$ for both), whereas lower doses of the drugs had no effect ( $p>.1$ for all) (Table 2). Comparisons of high dose clonidine and

Table 2. Effects of Clonidine and Guanfacine on Subjective Ratings for Sedation on Visual Analogue Scale

\begin{tabular}{lcc}
\hline & Placebo & Drug \\
\hline C 0.5 & $3.3 \pm 1.1$ & $3.0 \pm 1.7$ \\
C 2 & $3.2 \pm 1.4$ & $3.3 \pm 1.3$ \\
C 5 & $3.1 \pm 1.5$ & $5.0 \pm 1.3^{a}$ \\
G 7 & $3.0 \pm 1.3$ & $3.3 \pm 1.4$ \\
G 29 & $3.2 \pm 1.4$ & $4.5 \pm 1.3^{a}$
\end{tabular}

Note. Values (range 0-10; 1 representing not at all tired/sedated, and 10 representing extremely tired/sedated) represent ratings after completion of the test session (about $180 \mathrm{~min}$ after taking the study drug or matching placebo).

C, clonidine; G, guanfacine. Doses are expressed as $\mu \mathrm{g} / \mathrm{kg}$. Results are expressed as means \pm S.D.

${ }^{a}$ Two-tailed $p<.05$. 
guanfacine groups revealed no differences in the values of subjective feelings of sedation measured after placebo or drug (clonidine $5 \mu \mathrm{g} / \mathrm{kg}$ vs. guanfacine $29 \mu \mathrm{g} /$ $\mathrm{kg}$ ) treatments, or in the increase in subjective feelings of sedation induced by clonidine $5 \mu \mathrm{g} / \mathrm{kg}$ and guanfacine $29 \mu \mathrm{g} / \mathrm{kg}$ (i.e., clonidine $5 \mu \mathrm{g} / \mathrm{kg}$ - placebo vs. guanfacine $29 \mu \mathrm{g} / \mathrm{kg}$ - placebo; $p>.1$ for all). There were no significant sex or order effects or interactions between sex, order and drug group (data not shown).

\section{Blood Pressure}

Both systolic and diastolic blood pressures were reduced (group by repetition interaction: $\mathrm{F}(4,29)>3.7, p<$ .05 ; for systolic and diastolic blood pressures) by clonidine $5 \mu \mathrm{g} / \mathrm{kg}(T=-5.66, d f=7, p<$ for systolic values, $T=-3.25, d f=7, p<.01$ for diastolic values) and guanfacine $29 \mu \mathrm{g} / \mathrm{kg}(T=3.39, d f=11, p<.01$ for systolic values, and $T=2.57, d f=11, p<.05$ for diastolic values), whereas lower doses of the drugs had no effect on blood pressures $(p>.1$ for all) (Table 3$)$. There were no significant sex or order effects or interactions between sex, order and drug group (data not shown).

\section{DISCUSSION}

The Choice Reaction Time Test is analogous to the rat 5-choice serial reaction time task, which is considered to assess sustained attention and vigilance (Sahakian and Owen 1992). In the present study in young healthy volunteers, a non-subtype selective $\alpha_{2}$-adrenoceptor agonist, clonidine $5.0 \mu \mathrm{g} / \mathrm{kg}$, impaired performance in the Choice Reaction Time Test. Performance at easier levels of the test was unaffected by clonidine. Furthermore, simple motor performance was not impaired by clonidine. Thus, the deficits in the accuracy of responding in the Choice Reaction Time Test were not secondary to slowing or inaccuracy of motor performance.

In the Choice Reaction Time Test, clonidine $5 \mu \mathrm{g} / \mathrm{kg}$ both increased reaction latency and reduced the number of correct responses. It is likely that the slowed reac- tion latencies after clonidine $5 \mu \mathrm{g} / \mathrm{kg}$ were not simply due to sedation, as an equally sedating dose of guanfacine $(29 \mu \mathrm{g} / \mathrm{kg})$ as evaluated by self-ratings in visual analogue scale, had $\mathrm{n}$ o effect on reaction latencies or the number of correct responses. More likely, when treated with clonidine $5 \mu \mathrm{g} / \mathrm{kg}$, the study subjects may have tried to adopt a speed/accuracy trade-off strategy, i.e., by responding more slowly ("taking more time to think") they may have tried to maintain the tendency to respond deliberately at a lower level to reduce the possibility of responding inaccurately or too soon and so maintain a high level of response accuracy. The speed/ accuracy trade-off strategy interpretation is supported by previous animal data: when the performance requirements of the rat 5 -choice serial reaction time task are made more difficult, e.g., when the visual stimuli are made temporally unpredictable or the intertrial intervals are made longer than usual, the slower responding helps normal rats to maintain performance accuracy (Carli et al. 1983; Cole and Robbins 1987; Cole and Robbins 1992).

Importantly, the effects of clonidine and guanfacine on attentional performance vs. sedation and hypotension could be dissociated from each other. Both of the drugs, at the highest doses used (clonidine $5 \mu \mathrm{g} / \mathrm{kg}$ and guanfacine $29 \mu \mathrm{g} / \mathrm{kg}$ ), induced equal hypotension and subjective feelings of sedation. Recently, it was shown that the hypotensive and sedative response to $\alpha_{2}-$ adrenoceptor agonists was lost in mutant mice lacking functional $\alpha_{2 \mathrm{~A}}$-adrenoceptors, demonstrating that $\alpha_{2 \mathrm{~A}^{-}}$ adrenoceptors play a major role in these responses (Lakhlani et al. 1997). Thus, both clonidine and guanfacine at the doses that decreased blood pressure and increased sedation may have equally effectively stimulated $\alpha_{2 \mathrm{~A}}$-adrenoceptors. However, only clonidine 5 $\mu \mathrm{g} / \mathrm{kg}$ induced deficits in attentional (\% correct) performance and slowed responding. It is relevant to note that guanfacine has a higher $\alpha_{2 \mathrm{~A}} / \alpha_{2 \mathrm{C}}$ affinity ratio that may explain the different action on attention induced by guanfacine and clonidine treatments (Jansson et al. 1994). Indeed, clonidine may have modulated more strongly LC function (Quintin et al. 1986; Engberg and

Table 3. The Effects of Clonidine and Guanfacine on Blood Pressure

\begin{tabular}{|c|c|c|c|c|c|c|}
\hline & \multicolumn{3}{|c|}{ Placebo } & \multicolumn{3}{|c|}{ Drug } \\
\hline & $0 \mathrm{~min}$ & $+90 \mathrm{~min}$ & $+180 \mathrm{~min}$ & $0 \mathrm{~min}$ & $+90 \mathrm{~min}$ & $+180 \mathrm{~min}$ \\
\hline C 0.5 & $128 / 79$ & $126 / 78$ & $128 / 78$ & $126 / 78$ & $125 / 78$ & $127 / 79$ \\
\hline C 2 & $126 / 78$ & $126 / 78$ & $126 / 78$ & $126 / 78$ & $123 / 78$ & $122 / 75$ \\
\hline C 5 & $127 / 78$ & $125 / 77$ & $128 / 79$ & $127 / 78$ & $120 / 74^{a}$ & $114 / 70^{a}$ \\
\hline G 7 & $125 / 78$ & $124 / 78$ & $125 / 78$ & $124 / 79$ & $126 / 78$ & $128 / 80$ \\
\hline G 29 & $127 / 77$ & $129 / 78$ & $126 / 78$ & $129 / 77$ & $122 / 78^{a}$ & $117 / 75^{a}$ \\
\hline
\end{tabular}

Note. $+90 \mathrm{~min}, 90 \mathrm{~min}$ after taking the study drug or matching placebo, i.e., just before starting the test session; $+180 \mathrm{~min}, 180 \mathrm{~min}$ after taking the study drug or matching placebo, i.e. after completion of the test session; $C$, clonidine; $G$, guanfacine.

Doses are expressed as $\mu \mathrm{g} / \mathrm{kg}$ and blood pressure values (means of systolic/diastolic pressures) as $\mathrm{mmHg}$.

${ }^{a}$ Two-tailed , $p<.05$. 
Eriksson 1991) via $\alpha_{2 C}$ adrenoceptors and disrupted accuracy of attention and slowed responding. It is possible that clonidine stimulates striatal $\alpha_{2 C}$ adrenoceptors and slows responding by decreasing striatal dopamine metabolism (Sallinen et al. 1997). Indeed, reaction and movement latencies correlated with the disease severity in Parkinson's disease patients only at the most arduous level of the Choice Reaction Time Test (Riekkinen et al. 1998). Furthermore, reaction and movement latencies were prolonged by withdrawal of dopamine agonist and 1-dopa medication in all Parkinson's disease patients (Riekkinen et al. 1998). However, it is unlikely that the reduction of percentage of correct responses in the present study is due to a deficit in dopamine metabolism produced by clonidine treatment, since the percentage of correct responses were not reduced in Parkinson's disease patients by withdrawal of dopaminergic drugs. Another possibility is that clonidine may reduce the percentage of correct responses more effectively than guanfacine by suppressing thalamic function via $\alpha_{2 \mathrm{~B}}$ adrenoceptors and (Coull et al. 1997).

The doses of clonidine that have impaired attentional performance in healthy volunteers in previous studies have generally been lower than that required in the present task. Previously, in a measure of sustained attention, the rapid visual information processing test, clonidine at 1.5 and $2.5 \mu \mathrm{g} / \mathrm{kg}$ impaired performance (Coull et al. 1995a), and at $2.5 \mu \mathrm{g} / \mathrm{kg}$ it broadened the focus of attention (Clark et al. 1989; Coull et al. 1995b). $200 \mu \mathrm{g}$ of clonidine (about $2.9 \mu \mathrm{g} / \mathrm{kg}$ ) was sufficient to impair performance in a focused attention two-choice reaction time task (Smith and Nutt 1996), and to impair effortful information processing capacity (Frith et al. 1985). Even the most difficult level of the present Choice Reaction Time Test may be relatively easy for young healthy volunteers to perform. This could explain the failure to observe deficits in attentional performance by lower doses of clonidine in the present task.

Previous studies have investigated the effects of noradrenaline lesions and administration of $\alpha_{2}$-adrenoceptor agonists on performance in an analogous rodent task (Carli et al. 1983; Sirviö et al. 1994). These studies suggest that in rats, action of $\alpha_{2}$-adrenoceptor agonists does not seem to be mediated via depressed activity of dorsal noradrenergic bundle. A noradrenaline lesion in rats did not affect performance under baseline conditions, but reduced accuracy of responding under very challenging or distracting conditions (Carli et al. 1983). Administration of an $\alpha_{2}$-adrenoceptor agonist, dexmedetomidine, at baseline condition had no effect on attentional accuracy, motor function or motivation in rats (Sirviö et al. 1994). However, dexmedetomidine increased omissions and decreased responding during the intertrial interval, indicative of decreased vigilance (Sirviö et al. 1994). Therefore, in rats a distinction could be made between discriminative accuracy, which was selectively impaired by the noradrenaline lesion, and arousal that was diminished by treatment with an $\alpha_{2}$-adrenoceptor agonist. In the present study, clonidine did not increase omissions, but retarded reaction latencies and the percentage of correct responses. Therefore, in rats, an $\alpha_{2}$-adrenoceptor agonist only decreases vigilance (Sirviö et al. 1994), but in humans it can impair vigilance (i.e., increased subjective feelings of sedation) and also decrease attentional accuracy. The different profile of performance changes induced by $\alpha_{2}$-adrenoceptor agonists in rats and humans also makes it difficult to extrapolate to humans the conclusion of Sirviö et al. (1994) in rats that the action of $\alpha_{2}$-adrenoceptor agonists on Choice Reaction Time Test performance is not mediated via depressed activity of the ascending dorsal noradrenergic bundle nerves.

In conclusion, we observed that clonidine more effectively than guanfacine at doses that were equally hypotensive and sedative impaired attention. This result suggests that the inferior efficacy of clonidine compared with guanfacine to stimulate 'frontal' functions in humans may be due to attention defects (Jäkälä et al. 1999). Furthermore, the lower $\alpha_{2 A} / \alpha_{2 C}$ affinity ratio of clonidine (Jansson et al. 1994; Uhlen and Wikberg 1991) may explain the different action of these two compounds.

\section{ACKNOWLEDGMENTS}

Ewen MacDonald, Ph.D., is gratefully acknowledged for revision of the language of the manuscript. Research Nurse Markku Kalinen and psychologists Kosti Kejonen and Matti Vanhanen are acknowledged for their excellent technical assistance. This study was supported by the Finnish Academy of Sciences.

\section{REFERENCES}

Aghajanian GK, Cederbaum JM, Wang RY (1977): Evidence for norepinephrine-mediated collateral inhibition of locus coeruleus neurons. Brain Res 136:570-577

Aghajanian GK, VanderMaelen CP (1982): Alpha 2-adrenoceptor mediated hyperpolarization of locus coeruleus neurons: Intracellular studies in vivo. Science 215:13941396

Aoki C, Go C-G, Venkatesan C, Kurose H (1994): Perikaryal and synaptic localization of $\alpha$-2A-adrenergic receptorlike immunoreactivity. Brain Res 650:181-204

Arnsten AFT, Steere JC, Hunt RD (1996): The contribution of $\alpha_{2}$-noradrenergic mechanisms to prefrontal cortical cognitive function. Arch Gen Psychiatry 53:448-455

Arnsten AFT, Steere JC, Jetsch DJ, Li BM (1998): Noradrenergic influences on prefrontal cortical cognitive function: Opposing actions at postjunctional alpha1 versus alpha2-adrenergic receptors. Adv Pharmacol 42:764-767

Aston-Jones G, Shipley MT, Ennis M, Williams JT, Pieribone 
VA (1990): Restricted afferent control of locus coeruleus neurones revealed by anatomical, physiological, and pharmacological studies. In Heal DJ, Marsden CA (eds), The Pharmacology of Noradrenaline in the Central Nervous System. New York: Oxford University Press, pp 187-247

Berridge CW, Foote SL (1991): Effects of locus coeruleus activation on electroencephalographic activity in neocortex and hippocampus. J Neurosci 11:3135-3145

Björklund MG, Riekkinen M, Puoliväli J, Santtila P, Sirviö J, Scheinin M, Haapalinna A, Riekkinen P Jr (1998): Alpha2cadrenoceptor overexpressing mice are impaired in executing nonspatial and spatial escape strategies. Mol Pharmacol 54:569-575

Björklund MG, Sirviö J, Sallinen J, Scheinin M, Kobilka B, Riekkinen P Jr (1999): Alpha2c-adrenoceptor overexpression disrupts execution of spatial and non-spatial search patterns. Neuroscience 4:1187-1198

Borkowski JG, Benton AL, Spreen O (1967): Word fluency and brain damage. Neuropsychologia 5:135-140

Carli M, Robbins TW, Evenden JL, Everitt BJ (1983): Effects of lesions to ascending noradrenergic neurones on performance of a 5-choice serial reaction task in rats: Implications for theories of dorsal noradrenergic bundle function based on selective attention and arousal. Behav Brain Res 9:361-380

Cederbaum JM, Aghajanian GK (1976): Noradrenergic neurons of the locus coeruleus: Inhibition by epinephrine and activation by the alpha-antagonist piperoxane. Brain Res 112:413-419

Clark CR, Geffen GM, Geffen LB (1989): Catecholamines and the covert orientation of attention in humans. Neuropsychologia 27:131-139

Cole BJ, Robbins TW (1987): Amphetamine impairs the discriminative performance of rats with dorsal noradrenergic bundle lesions on a 5-choice serial reaction time task: New evidence for central dopaminergic-noradrenergic interactions. Psychopharmacology 92:458-466

Cole BJ, Robbins TW (1992): Forebrain norepinephrine: Role in controlled information processing in the rat. Neuropsychopharmacology 7:129-142

Coull JT, Middleton HC, Robbins TW, Sahakian BJ (1995a): Clonidine and diazepam have differential effects on tests of attention and learning. Psychopharmacology 120:322-332

Coull JT, Sahakian BJ, Middleton HC, Young AH, Park SB, McShane RH, Cowen PJ, Robbins TW (1995b): Differential effects of clonidine, haloperidol, diazepam and tryptophan depletion on focused attention and attentional search. Psychopharmacology 121:222-230

Coull JT, Frith CT, Dolan RJ, Frackowiak RSJ, Grasby PM (1997): The neural correlates of the noradrenergic modulation of human attention, arousal and learning. Eur J Neurosci 9:589-598

Downes JJ, Roberts AC, Sahakian BJ, Evenden JL, Morris RG, Robbins TW (1989): Impaired extra-dimensional shift performance in medicated and unmedicated Parkinson's disease: evidence for a specific attentional dysfunction. Neuropsychologia 27:1329-1343

Engberg G, Eriksson E (1991): Effects of alpha 2-adrenoceptor agonists on locus coeruleus firing rate and brain noradrenaline turnover in N-ethoxycarbonyl.2.ethoxy1,2-dihydroquinoline (EEDQ)-treated rats. NaunynSchmiedebergs-Arch-Pharmacol. 343:472-477

Foote SL, Morrison JH (1987): Extrathalamic modulation of cortical function. Ann Rev Neurosci 10:67-95

Frith CD, Dowdy J, Ferrier IN, Crow TJ (1985): Selective impairment of paired associative learning after administration of a centrally-acting adrenergic agonist (clonidine). Psychopharmacology Berl 87:490-493

Harley CW (1987): A role for norepinephrine in arousal, emotion, and learning? Limbic modulation by norepinephrine and the Key hypothesis. Prog Neuro-Psychopharmacol Biol Psychiatry 11:419-458

Hills M, Armitage H (1979): The two-period cross-over clinical trial. Br J Pharmacol 8:7-20

Jansson CC, Marjamäki A, Luomala K, Savola J-M, Scheinin M, Åkerman KEO (1994): Coupling of human $\alpha_{2}$-adrenoceptor subtypes to regulation of cAMP production in transfected S115 cells. Eur J Pharmacol Mol Pharmacol Sect 266:165-174

Jäkälä P, Sirviö J, Riekkinen P Jr, Haapalinna A, Riekkinen PJ (1992): Effects of atipamezole, an $\alpha_{2}$-adrenoceptor antagonist, on the performance of rats in a five-choice serial reaction time task. Pharmacol Biochem Behav 42:903-907

Jäkälä P, Sirviö J, Koivisto E, Kejonen K, Vanhanen M, Riekkinen P Jr (1999): Guanfacine, but not clonidine, improves planning and working memory in man. Neuropsychopharmacology 20:460-470

Kobilka BK, Matsui H, Kobilka TS, Yang-Feng TL, Francke U, Caron MG, Lefkowitz RJ, Regan JW (1987): Cloning, sequencing, and expression of the gene encoding for the human platelet $\alpha$-2-adrenergic receptor. Science 238: 650-656

Lakhlani PP, MacMillan LB, Guo TZ, McCool BA, Lovinger DM, Maze M, Limbird L (1997): Substitution of a mutant alpha2a-adrenergic receptor via 'hit and run' gene targeting reveals the role of this subtype in sedative, analgesic, and anesthetic-sparing responses in vivo. Proc Natl Acad Sci USA 94:9950-9955

Lee A, Wissekerke AE, Rosin DL, Lynch KR (1998): Localization of alpha2c-adrenergic receptor immunoreactivity in catecholiaminergic neurons in the rat central nervous system. Neuroscience 84:1085-1096

Langer SZ (1987): Presynaptic regulation of monoaminergic neurons. In Meltzer HY (ed), Psychopharmacology, The Third Generation of Progress. New York: Raven Press, pp 151-158

Lomasney JW, Lorenz W, Allen LF, King K, Regan JW, YangFeng TL, Caron M, Lefkowitz RJ (1990): Expansion of the $\alpha$-2-adrenergic family: cloning and characterization of a human $\alpha$-2-adrenergic receptor subtype, the gene for which is located on chromosome 2. Proc Natl Acad Sci USA 87:5094-5098

MacDonald E, Kobilka BK, Scheinin M (1997): Gene targeting-homing in on $\alpha_{2}$-adrenoceptor subtype function. Trends Pharmacol Sci 18:211-219

MacMillan LB, Hein L, Smith MS, Piascik MT, Limbird LE (1996): Central hypotensive effects of the $\alpha_{2 a}$-adrenergic receptor subtype. Science 273:801-803

McCormick DA (1989): Cholinergic and noradrenergic mod- 
ulation of thalamocortical processing. Trends Neurosci $12: 215-221$

Quintin L, Buda M, Hilaire G, Bardelay C, Ghigone M, Pujol JF (1986): Catecholiamine metabolism in the rat locus coeruleus as studied by in vivo differential pulse voltametry. III Evidence for the existence of an alpha 2-adrenergic tonic inhibition in behaving rats. Brain Res 375:235-245

Regan JW, Kobilka TS, Yang-Feng TL, Caron MG, Lefkowitz RJ, Kobilka BK (1988): Cloning and expression of a human kidney cDNA for an $\alpha$-2-adrenergic receptor subtype. Proc Natl Acad Sci USA 85:6301-6305

Riekkinen P Jr, Lammintausta R, Ekonsalo T, Sirviö J (1993): The effects of $\alpha_{2}$-adrenoceptor stimulation on neocortical EEG activity in control and 6-hydroxydopamine dorsal noradrenergic bundle-lesioned rats. Eur J Pharmacol 238:263-272

Riekkinen M, Kejonen $\mathrm{K}$, Jäkälä $\mathrm{P}$, Soininen $\mathrm{H}$, Riekkinen $\mathrm{P}$ Jr (1998): Reduction of noradrenaline impairs attention and dopamine depletion slows responses in Parkinson's disease. Eur J Neurosci 10:1429-1435

Robbins TW, Everitt BJ (1994): Arousal systems and attention. In Gazzaniga MS (ed), The Cognitive Neurosciences. Cambridge, MA, MIT Press, pp 703-720

Sahakian BJ, Owen AM (1992): Computerized assessment in neuropsychiatry using CANTAB: Discussion paper. J Royal Soc Med 85:399-402

Sallinen J, Link RE, Haapalinna A, Viitamaa T, Kulatunga M, Sjöholm B, MacDonald E, Pelto-Huikko M, Leino T, Barsh GS, Kobilka B, Scheinin M (1997): Genetic alteration of alpha2c-adrenoceptor expression in mice: Influence on locomotor, hypothermic, and neurochemical effects of dexmedetomidine, a subtype non-selective alpha2-adrenoceptor agonist. Mol Pharmacol 51:36-46
Scheinin M, Lomasney JW, Hayden-Hixson DM, Schambra UB, Caron MG, Lefkowitz RJ, Fremeau RT (1994): Distribution of $\alpha$-2-adrenergic receptor subtype gene expression in rat brain. Mol Brain Res 21:133-149

Sirviö J, Jäkälä P, Mazurkiewicz M, Haapalinna A, Riekkinen P Jr, Riekkinen PJ (1993): Dose- and parameter dependent effects of atipamezole, an $\alpha_{2}$-antagonist, on the performance of rats in a five-choice serial reaction time task. Pharmacol Biochem Behav 45:123-129

Sirviö J, Mazurkiewicz M, Haapalinna A, Riekkinen P Jr, Lahtinen H, Riekkinen PJ Sr (1994): The effects of selective $\alpha_{2}$ adrenergic agents on the performance of rats in a 5-choice serial reaction time task. Brain Res Bull 35:451-455

Smith AP, Wilson SJ, Glue P, Nutt DJ (1992): The effects and after effects of the $\alpha_{2}$-adrenoceptor antagonist idazoxan on mood, memory and attention in normal volunteers. J Psychopharmacol 6:376-381

Smith A, Nutt D (1996): Noradrenaline and attention lapses. Nature 380:291

Tanila H, Mustonen K, Sallinen J, Scheinin M, Riekkinen P Jr (in press): $\alpha_{2 \mathrm{C}}$-adrenoceptor knock out does not abolish the beneficial effect of dexmedetomidine, an $\alpha_{2}$-adrenoceptor agonist, on spatial working memory in mice. Eur J Neurosci

Uhlen S, Wikberg JES (1991): Delineation of rat kidney $\alpha-2 \mathrm{~A}$ and $\alpha$-2B-adrenoceptors with [3H]RX821002 radiologand binding: Computer modeling reveals that guanfacine is an $\alpha-2 \mathrm{~A}$-selective compound. Eur J Pharmacol 202:235-243

U'Prichard DC, Bechtel WD, Rouot BM, Snyder SH (1979): Multiple apparent $\alpha$-noradrenergic receptor binding sites in rat brain. Mol Pharmacol 16:47-60

Wechsler D (1992): Wechsler Adult Intelligence ScaleRevised. Manual. New York, NY, The Psychological Corporation 